Página inicial: 281 - Página Final: 287

Tipo de artículo: Reflexión derivada de investigación.

\title{
La tensión confianza/desconfianza entre lo académico y lo administrativo en la universidad.
}

\section{The Trust / Mistrust Tension between the Academy and the Management at University.}

\author{
Por: Andrés Felipe Londoño Vélez ${ }^{1}$
}

Recibido: junio de 2016 Revisado: noviembre de 2016 Aceptado: diciembre de 2016

\section{Resumen.}

La aparición de un escenario teleonómico como respuesta a la relación de los académicos y los administrativos universitarios, que es propiciada por una tensión confianza - desconfianza, que en la actualidad como diada polarizada no es explorada como oportunidad dialógica, sino como obstáculo de los intereses unívocos, tendría efecto sobre la relación de la universidad con la sociedad en la medida en que permitiría, también reconociendo otras tensiones, forjar una identidad en apertura de posibilidades en la que académicos y administrativos universitarios se vinculen a través de objetivos y propósitos.

Palabras clave. Administración universitaria, academia universitaria, conflictos administrativos, principio dialógico, teleonomía.

\section{Abstract.}

The appearance of a teleonomic scenario as an answer to the relation between university academics and staff, which is brought about by a trust-mistrust tension, which currently, as a polarized dyad, is not explored as a dialogical opportunity, but as an obstacle of univocal interests, would have an effect on the relation between university and society, inasmuch as it would allow, recognizing other tensions, as well, to forge an identity in favor of the possibilities in which university academics and staff are part through objectives and purposes.

Key words. University Administration, University Academy, Administrative Conflicts, Dialogic principle and Teleonomy.

\footnotetext{
${ }^{1}$ Psicólogo, Especialista en Alta Gerencia, Magister en Educación, Maestrando en administración de empresas con énfasis en recursos Humanos. Director de Registro Académico - Universidad de San Buenaventura Seccional Medellín. Medellín (Colombia) Contacto: director.registro@usbmed.edu.co ; psicoandres@hotmail.com
} 


\section{Introducción.}

La confianza y la desconfianza se constituyen en una bipolaridad que afecta al mundo de las relaciones humanas de manera significativa; cada uno de los elementos de esta diada polarizada tiene una importancia desde el contexto que se le analice, es así como para Lewicki, McAllister \& Bies (1998), refiriéndose a la confianza "su importancia radica en que sería el fundamento del orden social (citados por Yáñez, Ahumada \& Cova 2006, p.10), mientras que para Escovar (1980) los sentimientos de desconfianza "constituyen una reacción a las condiciones sociales y económicas existentes en la estructura social". En esta bipolaridad cada factor, en el mejor de los casos, se asume como diferente (Yáñez, Ahumada \& Cova 2006, p.10), sin embargo, en muchos de los casos, se asume la bipolaridad, de forma paradójica, como unipolar, en la que, por ejemplo, la desconfianza es solo la ausencia de confianza.

Estos conceptos antagónicos, no necesariamente deben estar separados o univocados, por el contrario, el tema de la confianza y la desconfianza pueden estar en el plano de una relación dialógica entre opuestos. Este tipo de relaciones son definidas por un principio conocido en el paradigma de la complejidad, y han sido nombradas con el nombre de dialogización que es "un principio de conocimiento que une o pone en relación ideas o principios de dos lógicas que de suyo son antagónicas. Esto es, él une dos principios o ideas que se excluyen mutuamente, pero que son inseparables dentro de una misma realidad o fenómeno" (Gómez Marín \& Jiménez, 2013, p. 3).

Como diada, ésta está vinculada a acciones que no ocurren en el presente, sino a escenarios posibles con los que nos relacionamos de modo consciente, para Laurence Cornu (1999), "la confianza es una hipótesis sobre la conducta futura del otro. Es una actitud que concierne el futuro, en la medida en que este futuro depende de la acción de otro"; lo que se constituye para este autor en "una especie de apuesta que consiste en no inquietarse del no-control del otro y del tiempo" (p.19).

La confianza y la desconfianza como conceptos viven en una tensión, que se entendería en palabras de Meirieu (1994), como un estado en el que la persona "debe hacer frente a exigencias contradictorias y no puede, sin ser incoherente, abandonar ninguna (...)” (p.87)

El objeto de este texto es explorar la tensión de esta bipolaridad, ese lugar vinculante de ambos conceptos que a la vez serían mutuamente excluyentes, y que se convierte en el lugar para proponer en términos de comunicación y relacionalidad, una estrategia que mantenga la vinculación dialógica entre los actores que configuran la universidad colombiana, sobre todo entre aquellos que con sus marcos de referencia comprenden la vivencia universitaria desde una sola mirada particular, y que con un poco de esfuerzo podrían encontrarse mirándola desde la tensión, que configuraría unos mínimos de encuentro con otras miradas particulares, posibilitando que "se pueda explicitar motivos y dar razones que justifiquen no solo el comportamiento sino los mismos sentimientos morales" (Hoyos, 2013, p.32), de las acciones propias de la dinámica universitaria.

\section{La Universidad.}


Para comenzar es necesario hablar de la universidad, como una estructura contextualizada, atada a las dinámicas de poder, en las que tiene un lugar y unas relaciones con el Estado y la Sociedad, pero, además, habitada por personas, que mantienen, controlan, reaccionan o se resisten al establishment.

En ese contexto, la universidad y quienes la habitan buscan su ethos, y lo encuentran desde cada una de las perspectivas desde las que comprenden a la universidad, es así como algunos lo encuentran en el universitas medieval o en el centro social de academia e investigación y otros en la metáfora empresarial, en la que la universidad es como una empresa; esta última metáfora, muy atrayente para escribir y el adecuado escenario para ubicar relaciones de confianza/desconfianza para este texto.

En el caso del símil entre universidad y empresa, éste logró minar el espacio conceptual entre ambas nociones, de una manera tan abrumadora, que lo que se estableció como metáfora la universidad es como una empresa, se convirtió en alienación de una a otra la universidad es_una empresa, tal como lo afirma Mollis (2005), "al quebrarse el contrato social con el Estado y ser arrojadas a las fuerzas del todopoderoso mercado, las universidades públicas y privadas de América Latina comenzaron a transitar la mercadotecnia” (p.6), o el mismo Noam Chomsky (2014), al decir que "todo esto sucede cuando las universidades se convierten en empresas, como ha venido ocurriendo durante las últimas décadas, cuando el neoliberalismo ha ido tomando por asalto cada una de las dimensiones de la vida" (Citado por Mendoza, 2014).

Este ethos empresarial encontrado por la universidad contemporánea, en el que no deja de ser foránea, por no ajustarte estrictamente a los cánones de ese mundo particular, la han puesto en escenarios en los que las críticas llegan de todas direcciones, por un lado cuando asume los valores completos del discurso dominante del mercado, se le responsabiliza de precarizar "la calidad de la enseñanza y el aprendizaje" y reproducir las "dinámicas autoritarias indeseables para las sociedades actuales" Chomsky (citado por Mendoza, 2014) y por el otro lado, si no asume de manera completa esos valores, se le entiende como "obsoleta, ruinosa e ineficiente" (2011) como titula un periódico digital madrileño, con respecto al Informe que diera CYD 2010 de la universidad española.

Ahora bien, éste inacabado ethos de la universidad contemporánea que la ha visto alejarse "de las causas sociales que le dieron origen (...), para convertirla en una corporación burocrática que se encuentre básicamente al servicio del mercado y la economía" (Ibarra-Colado, 2008, p.320), la ha llevado a un exagerado interés por la producción científica, en una suerte de "modelo Taylorfordista latente en el discurso contemporáneo" (Londoño, 2008, p.20), a una necesidad abrumadora por aumentar los recursos diferentes a matrícula, a la búsqueda incesante de contratos de operación de proyectos privados y públicos, que no pueden ser divulgados o que su divulgación tiene posturas unidas a grupos de interés como los farmacéuticos, negocios de tecnología, agencias militares o entes gubernamentales, sumado a lo anterior pero en contrasentido, como si se tratara de un compensación poética desfavorable, otorgando excesivas concesiones y libertades a los académicos, punto este al que "los portavoces oficiales del status quo académico han respondido, con raras excepciones, con tartamudeantes ineptitudes" MacIntyre (1992) (citado por Hoyos, 2013, p.24) .

Este escenario, en el que, se había planteado anteriormente, habitan personas que mantienen, controlan, reaccionan o se resisten al establishment, es el espacio propicio para la gesta de

\begin{tabular}{l|l|l|l|l|l|l} 
AGO.USB & Medellín - Colombia & Vol. 17 No. 1 & PP 1 - 323 & enero - junio & 2017 & ISSN: 16578031
\end{tabular} 
confianzas/desconfianzas, que para efecto del artículo se plantearan en un nivel de relación muy visible, la academia y administración universitaria.

\section{Tensión confianza/desconfianza entre Académicos/Administrativos.}

Dos fuerzas humanas dentro de la universidad se enfrentan en una lucha de dominación/sumisión/resistencia, con el único fin de privilegiar su discurso para el devenir institucional. Una, por un lado, reclama como los reyes de antaño, su derecho de sucesión del poder a cuenta del surgimiento medieval del Universitas, el origen de la agremiación de los dedicados al saber, y que otorga a los académicos la condición dominante para trazar en prospectiva el futuro de la Universidad. Por el otro lado, y acogidos en las dinámicas socioeconómicas de las últimas décadas, la globalización, el neoliberalismo y las fuerzas del mercado, un segundo grupo reclama esa condición dominante, en busca de eficiencia, eficacia y efectividad, con una postura determinante sobre los recursos disponibles, los retornos de la inversión y el posicionamiento de marca.

Dos fuerzas atadas en la cadena de valor de la universidad y en la tensión confianza/desconfianza. La observación y vivencia de la relación entre Académicos/Administrativos permite vislumbrar, las formas de comunicación y relacionalidad a través de un concepto planteado por Ulrich Beck (2000) un "discurso del riesgo" que comienza "donde la confianza en nuestra seguridad termina" (p.10), un discurso en que los intereses de cada una de las fuerzas están puestos en asuntos diametralmente opuestos, pero sistémicamente vinculados, por un lado, los académicos, ponen sus intereses en asuntos relacionados con la investigación, la formación y la transferencia de conocimiento, de asuntos como las artes, las ciencias, la filosofía, la técnica, la tecnología y las humanidades, mientras los administrativos universitarios ponen sus intereses en el aumento de la producción visible (científica, técnica y tecnológica), la satisfacción de clientes del servicio educativo, la búsqueda de ingresos sustitutos a la docencia, en el marco de la garantía de efíciencia y eficacia.

Ambas fuerzas tienen al mismo tiempo una tentación subordinadora de la otra, es así como la academia espera una suficiente provisión de recursos y talentos, para su ejercicio sustantivo, sin cuestionamientos, papeleos, controles y supervisiones, sin la burocracia criticada por Chomsky (2014), y la administración espera más obediencia, más resultados, más control de producto o servicio y mayor retorno en la inversión de recursos.

Estas relaciones mediadas por la tentación subordinadora, estiran y contraen la tensión confianza/desconfianza, dado que los asuntos relacionados con las formas de operación de cada fuerza, son en la mayoría de los casos desconocidas entre ellas, es así como el administrativo, desconoce la función de la reflexión, criticidad, búsqueda de autonomía, consagración al saber y búsqueda de las verdades de la naturaleza y el espíritu que hace el profesor, y el académico ignora las afujías presupuestales, las complejidades de la planificación organizacional, la competencia entre universidades, las dinámicas de la oferta y demanda de talento humano calificado, que vive el administrador.

Estos desconocimientos mutuos amplifican el discurso del riesgo, poniendo a cada uno, en un lado de la balanza, y no como se esperaría, en medio de la tensión. El encuentro en la confianza/desconfianza, que significa poner en dialogo ambos polos a través de la tensión, se le

\begin{tabular}{l|l|l|l|l|l|l} 
AGO.USB & Medellín - Colombia & Vol. 17 No. 1 & PP 1 - 323 & enero - junio & 2017 & ISSN: 16578031
\end{tabular} 
podría dar el nombre de certidumbre/incertidumbre, dependiendo del lugar en el que se encuentre, así, si la tensión confianza/desconfianza está muy dilatada, existe mucha incertidumbre, lo que crea miedo y la tensión corre el riesgo de convertirse en tan solo desconfianza, pero si por el contrario, la tensión esta disminuida, existe certeza y predictibilidad, la tensión se convierte en solo confianza. La relación centrada únicamente en desconfianza, genera distanciamiento, mientras que la relación centrada únicamente en la confianza genera ingenuidad.

El marco de referencia del académico y del administrativo, es distinto para ver el mismo fenómeno en el contexto de la universidad-empresa, sin embargo, cabe la posibilidad de encontrar en la tensión una posibilidad dialógica, que además cree un escenario teleonómico como alternativa. La posibilidad dialógica permitiría a la administración y la academia caminar juntos y en posibilidad de encontrar algunas coaliciones que desarrollan la estructura de la Universidad, con un marco ético, que permita que todos los propósitos que se emprendan han de ser buenos. Ahora bien, el escenario teleonómico (haciendo referencia a los postulados de Jacques Monod) permite crear propósitos, cuya característica, en lo que refiere a su construcción y reconstrucción, es plantearse en clave de realidad actual, lo anterior permitiría la renuncia a lo teleológico como única opción, dado que no se tendría que ir tras metas y escenarios posibles (creados del concepto de futuro del pasado), sino que se realizaría una trashumancia que crea propósitos coherentes con el tiempo presente, lo que asegura la coherencia entre el ideal, la acción de la estructura y el resultado en términos presentes.

Estos propósitos deben poblar tanto los discursos idealizados, prometidos y vinculantes, como aquellos racionales y realistas (en última medida más dominantes) para que, en el cumplimiento de su misión pública, la universidad, pueda llevar a cabo los ejercicios sustantivos de la docencia, la investigación y la extensión.

El escenario teleonómico permitido gracias al reconocimiento y aceptación de la tensión, facilitaría a la universidad en el ejercicio de sus funciones, aceptar tanto un encargo social eminentemente materialista de reproducción de fuerzas de trabajo, como también, la posibilidad de tratar de cambiar lo instituido resistiéndose a esos mismo discursos dominantes, encargos sociales que más que contradictorios, son dialógicos, porque la universidad en ese escenario se vitaliza por la tensión y entra en acción por los propósitos.

Los actores encontrados en acuerdos mínimos o propósitos al interior de la estructura serían el punto para encontrar una identidad compleja de la Universidad, que puede en tensión confianza - desconfianza, proyectar hacia afuera su posibilidad de mantener las fuerzas productivas y económicas de la sociedad, al tiempo que garantiza un propósito de formación para la autonomía del ser.

Lo anterior implica mantener el orden social y al mismo tiempo romperlo, dado que un ideal subrepticio del sustrato social sería eclosionar, permitir a algunos salir del cascarón y lograr la anhelada emancipación.

Con ese contexto la sociedad, que somos todos y no es ninguno en particular, generaría igualmente relaciones de confianza y desconfianza con la universidad como dispositivo, porque de allí emergen personas autónomas que cuestionan lo instituido y lo cambien, al mismo tiempo 
que, personas que, por el contrario, se unen de manera voluntariosa a la estabilización de las estructuras.

Un escenario teleonómico en el que se reconozca la tensión y se mantenga, favorece que los que se dejaban seducir por la subordinación de aquel con un pensamiento diferente, comprendan que es el propósito y los objetivos éticos, los que permiten el cumplimiento de cualquier institución, lo que retira la atención del problema universidad-empresa, y lo pone en lugares más importantes.

\section{Conclusiones.}

La bipolaridad confianza - desconfianza afecta el mundo de las relaciones humanas de manera significativa, dado que con ello construimos ambientes de posibilidad, pero también limitamos nuestra cercanía con los otros y lo otro.

El marco de referencia de las personas que trabajan en el mundo académico y de los que trabajan en la administración de las Universidades, es distinto para ver el mismo fenómeno en el contexto de la universidad-empresa, sin embargo, cabe la posibilidad de encontrar en la tensión que ambos marcos generan una posibilidad dialógica, que además cree un escenario teleonómico como alternativa.

Un escenario teleonómico en la Universidad permite el reconocimiento y aceptación de las diferentes formas de ver los fenómenos, así estén en tensión, posibilitando a la universidad un ejercicio de sus funciones y de su encargo social.

Los actores encontrados en acuerdos mínimos al interior de la universidad serían el punto para encontrar una identidad compleja de la Universidad.

\section{Bibliografía.}

Beck, U. (2000). Retorno a la teoría de la sociedad del riesgo. Boletín de la A.G.E.(30), 9-20. Obtenido de http://www.age-geografia.es/ojs/index.php/bage/article/view/383

Cornu, L. (1999). a confianza en las relaciones pedagógicas Construyendo un saber sobre el interior de la escuela. Buenos Aires: Ediciones Novedades Educativas.

Escavar, L. (1980). Efectos de la estructura social y la alienación sobre las actitudes interpersonales de los campesinos. Revista Latinoamericana de Psicología, 12(1), 37-49. Obtenido de http://www.redalyc.org/articulo.oa?id=80512104

Gómez Marín, R., \& Jiménez, J. A. (2013). De los principios del pensamiento complejo. Revista Big Bang Faustiniano, 2(1), 3-5. Obtenido de http://web.unjfsc.edu.pe/index.php/Bigbang/article/view/23/297

Hoyos Vásquez, G. (2013). El ethos de la universidad. Medellín: Fondo Editorial Universidad EAFIT. 
Ibarra-Colado, E. (2008). Regulación social de la 'triple hélice' en América Latina: Diálogos en busca de un proyecto distinto. Revista mexicana de investigación educativa, 13(36), 319-327. Obtenido de http://www.scielo.org.mx/scielo.php?script=sci_arttext\&pid=S140566662008000100016

Londoño, A. F. (2008). Contenido del discurso contemporáneo sobre la administración del talento humano docente de las instituciones universitarias privadas de la ciudad de Medellín. REVISTA Universidad EAFIT, 44(151), 10-23. Obtenido de http://publicaciones.eafit.edu.co/index.php/revista-universidadeafit/article/view/128/123

Meirieu, P. (1994). En la escuela hoy. Editorial Octaedro.

Mendoza, M. L. (13 de marzo de 2014). "El neoliberalismo tomó por asalto a las universidades": Noam Chomsky. Obtenido de www.elespectador.com: http://www.elespectador.com/noticias/educacion/el-neoliberalismo-tomo-asaltouniversidades-noam-chomsk-articulo-480438

Mollis, M. (2003). Las universidades en América Latina: ¿Reformadas o Alteradas? La cosmética del poder financiero. Buenos Aires: Clacso. Obtenido de http://biblioteca.clacso.edu.ar/clacso/gt/20101109010429/mollis.pdf

Yáñez Gallardo, R., Figueroa, L., \& Cova Solar, F. (2006). Confianza y desconfianza: dos factores necesarios para el desarrollo de la confianza social. Universitas Psychologica, 5(1), 9-20. Obtenido de http://www.redalyc.org/pdf/647/64750102.pdf 